\title{
DOS JUECES EQUIVOCADOS: CLAMENCE Y EL GRAN INQUISIDOR
}

\author{
Two judges wrong: Clamence and the Grand inquisitor
}

Ali Viquez*

\section{RESUMEN}

En este ensayo se compara a los personajes de Clamence (La caída, Albert Camus) y el Gran Inquisidor (Los hermanos Karamázov, Fiodor Dostoievski) y se sostiene que ambos cometen errores de juicio similares, dada la generalización apresurada del mal en que incurren.

Palabras clave: Literatura comparada, literatura francesa, literatura rusa, novela francesa contemporánea, novela rusa del siglo XIX.

\begin{abstract}
This paper compares the characters of Clamence ( La caida, Albert Camus ) and the Grand Inquisitor (Los hermanos Karamazov, Fyodor Dostoyevsky) and argues that both make mistakes similar trial, given the hasty generalization of evil incurred.

Key Words: comparative literature , French literature , Russian literature , contemporary French novel, nineteenth-century Russian novel.
\end{abstract}

Universidad de Costa Rica, Profesor, Escuela de Filología, Lingüítica y Literatura. Costa Rica.

Correo electrónico: aviquez@yahoo.com

Recepción: 10/2/16. Aceptación: 20/2/16. 


\section{Introducción}

Las comparaciones entre Camus y Dostoievski no son novedosas, habida cuenta de que el primero nunca negó la importancia que concedía al pensamiento del segundo; más bien, vertió una magistral lectura de los personajes de Iván Karamázov, Chigaliev y Kírilov en $E l$ hombre rebelde, y hasta realizó una adaptación teatral de Los demonios. (Esto, solo para citar los dos ejemplos más conocidos, pero se encuentran muchas más referencias en la obra de Camus: véase Dunwoodie (1996) y Davison (1997).) Aquí pretendo desarrollar una comparación entre Clamence (narrador protagonista de $L a$ Chute) y el Gran Inquisidor (personaje de Los hermanos Karamazov), vistos ambos en su calidad de jueces de la humanidad entera, un rol que los personajes se atribuyen a sí mismos abierta y unilateralmente.

Elizabeth Trahan (1966) puso el énfasis en la relación de Clamence con los protagonistas de Memorias del subsuelo y "El sueño de un hombre ridículo" y propone (y niega) muy someramente el vínculo entre los dos que a mí me ocupan: "Clamence is not simply another Grand Inquisitor, a victim of his own creed." (1966: 345) Más adelante, se detiene un poco más: "Clamence, who begins with Nietszche, with an affirmation of man's need of power, seems to end with the Grand Inquisitor, a false pope, a false prophet who establishes an arbitrary rule over a mankind united by slavery. But Clamence lacks even the stature of a Grand Inquisitor." (347) Sugiere que Clamence es un personaje que al lado del Inquisidor parece mezquino, pues solo se preocupa por su suerte personal, busca culpar a los demás para librarse de la culpa que recae sobre él mismo, mientras que el Inquisidor ni siquiera juzga a los otros, sino que los compadece. Difiero de esta lectura y este ensayo se propone demostrar por qué.

Por su parte, Myrna Margnan-Shardt (citada en Zepp, 1982) prefiere acercarse a la comparación desde el punto de vista formal y así apunta: "Notre hypothèse consiste à affirmer que Camus, dans La Chute, s'exprime a travers un genre littéraire que l'on trouve souvent dans la tradition russe, et plus particulièrement pour notre propos dans l'oeuvre de Dostoïevski. Ce genre littéraire est le skaz... Par ce terme nous entendons un récit ou l'auteur, en décrivant l'univers particulier du héros, cède sa place et sa parole au personnage principal ou se laisse contaminer par le style propre à celuici." (256) De aquí puede deducirse una relación más específica de La Chute con el pasaje del Gran Inquisidor, en el cual se produce un skaz, ya que la narración está a cargo de Iván Karamázov ${ }^{1}$. Esta es una lectura interesante, pero no es mi propósito el indagar en las cuestiones más formales y -como he señalado en la nota $1-$ no exentas de cierta polémica. Sí rescataré la importancia de que los personajes (y ahora me refiero al Gran Inquisidor, no a Iván, y por supuesto a Clamence) toman la palabra de manera exclusiva, algo sobre cuyas consecuencias filosóficas intentaré ahondar.

Otra aproximación que me interesará tomar en cuenta es la de Hervé Pasqua (1990), quien desarrolla la idea de que Camus concibe el mal como una fuerza motriz primordial en el universo, idea que deberé matizar ya que esta postura debe atribuirse al narrador, no al autor, y que resultará importante a la hora de comparar a Clamence con el Gran Inquisidor, quien asimismo se imagina al mal en el origen mismo -si no del universo, al menos sí de lo humano. Y, aunque un poco más alejado de lo que voy a tratar, el trabajo de Daniel Just (2010) en el que diferencia la culpa y la vergüenza (guilt and shame) y se adentra en La chute, me será de mucha utilidad, no solo por lo que propone sino por la información que proporciona sobre la recepción que la novela de Camus tuvo cerca de su publicación, en particular en las figuras de escritores tan importantes como Blanchot y Sartre. Llama la atención que mientras el primero se esforzó en remover lo más posible la culpa del personaje de Clamence, en quien ve a una figura llena de lucidez existencial, el segundo declaró que esta novela de la culpa y la mala conciencia era la mejor obra de Camus, una valoración que no resultará nada compartida, 
pero hay que tomar en cuenta lo siguiente: "According to Sartre, guilt has to be cultivated because it stimulates action..." (Just 2010: 911).

Ray Davison (1997) expresa la opinión generalizada de que La Chute es la obra camusiana en la que se nota más fuertemente el influjo de Dostoievski. Sostiene que formalmente la técnica de la confesión monológico-dialógica remite a Memorias del subsuelo y a Crimen y castigo, y profundiza en la relación temática de la primera de estas novelas dostoievskianas con el texto camusiano. Muy llamativo me resulta su hallazgo de que Clamence pervierte la idea del “comunismo espiritual" de Zósima, el personaje que en Los hermanos Karamázov es el estricto reverso del Gran Inquisidor:

Central to Clamence's "philosophy" is the idea of individual guilt. It is impossible to establish truth and innocence but of guilt we can be certain because we are all judges: "puisque nous sommes tous juges, nous sommes tous coupables les uns devant les autres", says Clamence, who earlier declares: «nous ne pouvons affirmer 1'innocence de personne, tandis que nous pouvons affirmer à coup sûr la culpabilité de tous. Chaque homme témoigne du crime de tous les autres» (...) These statements both echo and pervert the basic propositions of what Camus called elsewhere «le communisme spirituel de Dostoïevski ... la responsabilité morale de tous». These reciprocal, moral propositions, which underpin Dostoievsky's faith, find expression in the pronouncements of Zosime : «chacun de nous est coupable devant tous pour tous et pour tout... souviens-toi que tu no peux être le juge de personne» (Davison 1997: 1682

Davison también examina el nexo de Clamence con el Gran Inquisidor, y establece que el primero reproduce el pensamiento del segundo en relación con el problema de la libertad y la esclavitud, ya que ambos consideran que la libertad es un fardo demasiado pesado, que la mayoría de las personas desearían dejar de cargar: "The essential components of Clamence's visión of a master-race assuming the burden of freedom and guilt for the enslaved are all clearly in evidence" (1997, p 173) Luego profundiza en este problema estudiando más bien el texto de Los demonios, al que Camus dio atención preferente en L'homme révolté, cuando se refirió al "chigalievismo", una tendencia política que -aunque al principio es objeto de burlas por parte de personajes como Verjovenski hijo-termina por atraer a tantos que Camus la ve como la primera versión de los totalitarismos que azotaron el siglo XX.

Por su parte, Peter Dunwoodie (1996) estudia los intertextos dostoievskianos de $\mathrm{La}$ Chute, que identifica como Memorias del subsuelo, Crimen y castigo, El doble y "El sueño de un hombre ridículo". Su libro presenta un fuerte anclaje teórico en los postulados sobre la novela dialógica según Bajtín. Además, atribuye a Dostoievski la creación previa de la figura del "juez-penitente", en la que se basa el personaje de Clamence, y justifica esta atribución con una interesante cita del Diario de un escritor ${ }^{3}$ :

«Puisque (...) j'assume à la fois le rôle du plaignant et celui du répondant, de l'accusé et du juge, et puisque je trouve cette comédie de la part de la nature tout à fait stupide, et que même j'estime humiliant de ma part d'accepter de la jouer...

«En ma qualité indiscutable de plaignant et de répondant, de juge et d'accusé, je condamne cette nature qui, avec un si impudent sans-gêne, m'a fait naître pour souffrir... » (Ess 182)

La révolte philosophique, le bouleversement psychique, l'accouplement forcé de rôles opposés et les formules de mise en accusation emphatiques qui sont exposés ici annoncent Clamence... (Dunwoodie, 1996, p 135)

Cuando trata a Clamence en tanto juez, Dunwoodie pone todo su interés en la figura del comisario Porfirio Petrovich, de Crimen y castigo.

Mi objetivo es entonces -ya salta a la vista-comparar las concepciones del ser humano en las cuales se afianzan los personajes de Clamence y el Gran Inquisidor, dos jueces que tienen la ambición de poder juzgar a la humanidad entera. Parto del hecho de que ambos personajes aspiran a representar no solo casos aislados, sino que se ofrecen como los exponentes de actitudes y tendencias presentes en el mundo: como prueba de ello, ofrezco ya el hecho de que aparecen como "falsos papas". Esto se puede interpretar como que los dos 
personajes representan figuras de autoridad que se erigen en la práctica. Volveré sobre el tema.

\section{El Inquisidor}

A su manera peculiar, el Gran Inquisidor (personaje en el que se transluce, sin nombrársele así, a Tomás de Torquemada) viene a ser un filántropo. Ficción de segundo grado, puesto que es hijo de la imaginación de un personaje, Iván Karamázov, tiene toda la libertad para relacionarse con su referente histórico sin deber darle cuentas a la realidad: Iván es un personaje imaginario que crea a otro personaje imaginario; pedirle que se ajuste a los hechos sería tanto como pedírselo a don Quijote, sueño de un sueño de Cervantes, en palabras de Borges.

En su más amplio sentido, la filantropía implica una preocupación por el bienestar de los seres humanos que no necesariamente parte del hecho de juzgar positivamente a esos seres humanos. No se trata de concebir como merecedoras del bien a las personas que el filántropo pretende favorecer. Desde cierto punto de vista, podríamos incluso pensar que es más filantrópica la actitud de quien, no siendo un humanista convencido de las virtudes de las mujeres y los hombres, actúa a favor de todos ellos, que la de quien sí considera al ser humano digno de la ayuda que le ofrece. El inquisidor se halla en la línea de lo que podríamos llamar los "filántropos no humanistas", puesto que, sin creer en la bondad ni la nobleza de las personas, aun así desea ayudarlas.

Lo diré sin ambages: el Inquisidor está convencido de la pequeñez moral de las personas. Las concibe como unos entes cobardes frente a la verdad, que preferirán cualquier mentira consoladora antes que un enfrentamiento con los hechos de la vida. Al menos, así lo piensa de una enorme mayoría: “...millones de seres humanos, también criaturas de Dios, quedan sujetos solo al escarnio, pues nunca tendrán fuerzas suficientes para hacer uso de su libertad, y de rebeldes lamentables no saldrán nunca gigantes." (Dostoievski, 1983: 321) Esta enorme mayoría incapaz de sobrellevar el peso de su propia libertad estará dispuesta a todo con tal de perderla, o mejor dicho, con tal de engañarse $\mathrm{y}$, habiéndola perdido en la práctica, pensar que aún la tiene. De este modo, consigue vivir sin el agobio de ser libre y se miente a sí misma para no tener que aceptar que ha sacrificado voluntariamente esa condición que tanto miedo le daba. Al ser humano en general lo atormenta el ejercer la libertad: prefiere que le digan qué hacer, prefiere que quiten de sus hombros el peso de tener que elegir y responsabilizarse por sus elecciones. Es de este tremendo tormento, de esa angustia asfixiante, que se ocupará la Inquisición.

Al someter a los fieles a la autoridad de la iglesia, esta les hace el favor de librarlos del ejercicio de su libertad. Pero no deja que sepan que están esclavizados (aunque en el fondo no se necesitaría demasiada perspicacia para darse cuenta, pero aquí aplica aquello de que "no hay peor ciego que el que no quiere ver") y les da un norte obligatorio al cual orientarse. En qué creer, cómo actuar, qué esperar para bien (la salvación tras la muerte) y para mal (el infierno a la larga y la tortura a la corta): todo está resuelto para todo el mundo.

O, más bien, para casi todo el mundo. Resta una minoría que está compuesta por los más valientes y más lúcidos, entre ellos, el primero, el Gran Inquisidor. Estos no temen ejercer la libertad; lo hacen tomando las decisiones por el resto. Y saben el gran secreto que Aliosha Karamázov, con sorpresa, revela: el Inquisidor es ateo. Una minoría especialmente inteligente sabe la verdad de que no hay Dios, pero la oculta ante los cobardes que tampoco podrían con esto.

Ahora llego a lo que en el fondo me proponía establecer: ¿Qué clase de juez es el Gran Inquisidor? En primer lugar es el juez de todos los seres humanos, en el sentido de erigirse en quien los califica $\mathrm{y}$, sobre esta base, los clasifica. Una gran mayoría cobarde e incapaz de ejercer su libertad, ansiosa de una felicidad que el tormento de ser libres no permite obtener. Una minoría valiente que, tomando la libertad de todos sobre sus hombros, no duda en someter a los otros, y ejerce la filantropía al permitirles 
ser felices a los cobardes y a los tontos, que no pueden y no quieren decidir ni pensar por sí mismos. Esta minoría sabe que no hay Dios y --al estilo de un San Manuel Bueno, mártir, el personaje de Unamuno-piadosamente oculta esta verdad, que provocaría la desesperación de muchos.

En segundo lugar, el Inquisidor es el juez despiadado de los que se oponen al funcionamiento de su esquema para visualizar la realidad humana. Irán a la hoguera quienes pretendan romper con este orden de cosas que asegura la felicidad de las masas pusilánimes y ciegas. Tal vez no sea así para muchos condenados, que se quemarán por cuestiones meramente circunstanciales, algún tipo de mala conducta que debe ser castigada aunque en el fondo no pone en riesgo las verdades asentadas por la Inquisición: en estos casos, se violentará el cuerpo pero el "alma" seguirá a salvo, con el consuelo de creer en la verdad establecida firmemente por el poder. Son aquellos condenados que seguramente cuestionan la justicia que se les aplica a ellos en particular, pero no las verdades sobre las cuales se asienta el sistema que los juzga: dirán, si acaso, "yo no he cometido tal o cual crimen". Estos no son tan peligrosos.

El verdadero peligro estriba en aquellos que cuestionan lo que el Inquisidor ha establecido como el orden inamovible que ya hemos comentado. Son estos los que deben pasar más rápido a la hoguera, antes de que puedan hacer que algo cambie y, con ello, se pierda la única felicidad posible para las grandes mayorías. Eso está claro: el Inquisidor piensa que no hay otra senda hacia alguna dicha que la que él ha trazado. Por ello, perseguir a los que ponen en peligro al orden inquisitorial es defender a la humanidad misma. Su filantropía lo lleva a la paradoja de condenar al fundador histórico de su religión: el relato del Gran Inquisidor termina con la condena de un Cristo que ha venido por segunda vez y sería capaz de destruir la obra de quince siglos de la Iglesia católica, si vuelve a interesar a las masas en el ejercicio de la libertad.
Termino con una observación que retomaré más tarde: el Cristo que vuelve a la España del siglo XV (ubicación espacio temporal del poema de Iván Karamázov) guarda completo silencio.

\section{El juez-penitente}

Jean-Baptiste Clamence tiene un apellido significativo. Del latín clamare (proclamar), también alude a la clemencia (véase Yalom, 2003: 446). Y evidentemente el primer nombre remite al personaje evangélico encargado de anunciar la venida del Cristo. ¿Qué es lo que proclama, qué es lo que anuncia este personaje? Al fin de cuentas, y después de muchos rodeos (los cuales, según él mismo termina por confesar, no eran casuales, sino una forma planeada de vender a su interlocutor la verdad de su idea), se trata de su propia culpa, que está purgando sin fin. Es un penitente, un parisino que paga en el exilio voluntario de Amsterdam por el crimen cometido.

Pero vivir en Amsterdam, retirado de su exitoso ejercicio previo como abogado, no constituye lo esencial de su castigo. Clamence se ha autocondenado a repetir su historia: da cuenta, una y otra vez, de su culpa, ante interlocutores diversos. Así, su castigo se cumple en lo fundamental como una enunciación ejecutada una vez tras otra, es un acto de palabra al que podemos calificar de performativo: hace la penitencia al tiempo que la dice. $\mathrm{Y}$ esa penitencia coincide, punto por punto, con el texto que leemos.

Se nos remite nuevamente al universo cristiano: los católicos también ejecutan sus penitencias, luego de la confesión verbal, por medio de oraciones, es decir, por la palabra. Camus coincide con Dostoievski en una adhesión general al mundo cristiano, al menos en esta novela. Y si en Dostoievski ello es una decisión consciente y explícita, lo cierto es que en Camus el panorama se plantea menos transparente: parecería más bien que aquí la visión de mundo cristiana, con su omnipresente patetismo de 
la culpa, se impone incluso si no se concibe la divinidad del Cristo.

Y ¿de qué es culpable Clamence? ¿Cuál es el crimen que ha cometido, por el cual, por cierto, solamente él se sabe culpable ${ }^{5}$ ? Clamence se ha dado cuenta de que, después de creerse un adalid de la justicia y el bien durante buena parte de su existencia, no ha hecho en realidad nada más que complacerse a sí mismo teniéndose por bueno. Como abogado litigante, ha invertido su vida en la defensa de los pobres y los débiles, y lo ha hecho sin buscar grandes retribuciones económicas, pero no sin un interés egoísta. Según lo apunta Daniel Just, Clamence (otra vez el universo cristiano), se parece a San Agustín: "Like Saint Augustine, who reports a similar, if even more ingenuous, fondness for the suffering of others, Clamence admits that he did not want to erradicate injustices, for they allowed him to be popular and to feel good about himself" (2010: 899-900)

Así pues, Clamence se descubre a sí mismo como un exponente de una moral dudosa: cual dama de la caridad, que socorre al tiempo que hace notar su bondad y contribuye con migajas para que no resulte insostenible una pobreza que, en el fondo, no quiere combatir. Clamence se da cuenta de que su militancia al lado de los débiles no tiene más propósito que el reconocimiento. La buena conciencia que crea para sí al abogar por los necesitados es la fachada de una cómoda posición en la que tanto la injusticia como su papel de héroe cotidiano se perpetúan.

Dos acontecimientos precipitaron que cayera la venda con que se cubría para no saberse culpable: primero, el incidente con un motociclista y otro individuo que lo agreden, por una mera disputa en el tráfico. Como Clamence no consigue tomar venganza de ellos, se da cuenta de que alberga un terrible desprecio no solamente hacia esos dos extraños, sino hacia todo aquel que no esté dispuesto a profesarle admiración. Clamence se descubre así enteramente necesitado de la aprobación de los otros, y muy propenso al odio y la violencia cuando no la consigue. Además, Clamence se da cuenta, en la animadversión espontánea hacia su persona que se despertó en los testigos del incidente, de que el reconocimiento que aparentemente se le profesa esconde una profunda envidia: es por su facha "exitosa" que lo malquieren.

El segundo incidente es más importante, e incluso da origen al título de la novela. Clamence ha sido testigo, completamente pasivo, de la caída de una joven al río Sena. Un aparente suicidio. Lejos del aplauso, en la oscuridad y la soledad de la noche, no ha movido un dedo para salvarla. Con la caída de la muchacha cayó también la máscara con la que Clamence se admiraba complacido en el espejo: ahora no le queda más que verse como alguien que, si no cobra (no en metálico, pero sí en alabanzas para su buen corazón), no está dispuesto a actuar ${ }^{6}$.

Clamence, que hasta entonces no podía entender cómo alguien podía dedicarse a ser juez de los demás, adquiere el papel de juez de sí mismo. Y tras probar a suavizar el desprecio que siente ante su propia persona por medio básicamente del alcohol y las mujeres, se entera de que no consigue olvidar. Los excesos que comete con el cuerpo no acallan su mala conciencia, más bien se suman a su lista de arrepentimientos. Pero entonces le surge la idea de irse de París, donde ya lo conocen, y comenzar otra vida, con otro nombre, como “juez-penitente". No logrará la salvación, pero al menos obtendrá una penitencia que le permitirá vivir dedicado a ella.

Ya hemos visto cómo la va ejecutando. Ahora bien, Clamence también se da cuenta de que le es imposible mirar a los otros sin juzgarlos tan culpables como lo es él. Aquel que nunca quiso ser un juez advierte que jamás ha dejado de serlo; es más, encuentra inevitable juzgar a los demás. Por eso su confesión, que es su penitencia, resulta también un juicio de quien lo escucha. Clamence ejecuta una proyección de su culpa en el interlocutor de turno: este, salvo los casos de héroes o santos muy poco probables, habrá de reconocerse en la figura del penitente que habla. Al final, Clamence le anuncia a su interlocutor que la historia entre ellos no termina: se ha asegurado de sembrarle la semilla de la culpa. Es Juan el Bautista que proclama: 
“Tras de mí vendrá lo más importante. Y eso será cuando te confieses a ti mismo que eres igual que yo: tienes la misma culpa." El que escucha es el lector, en el fondo, y Clamence lo (nos) señala con el dedo acusatorio al estilo Baudelaire: "Hypocrite lecteur, -mon semblable, --mon frère".

Clamence los juzga a todos; se condena a sí mismo y a los demás también. En cuanto a lo que su interlocutor tenga que decir, ello no forma parte de la novela. Es silencio.

\section{Dos jueces equivocados}

Clamence y el Gran Inquisidor son dos jueces convencidos de su derecho a juzgar a los demás. Ahora bien, el juicio tiene una base en el conocimiento: ellos pueden juzgar porque son lúcidos; lo hacen porque conocen. Solamente quien se mantenga en la ignorancia acerca de la humanidad no la juzga: esta es una idea que -en el caso de Clamence-es explícita. El abogado no concebía cómo alguien querría ser juez; una vez que reacciona ante la caída de la mujer, advierte que cualquier conocimiento que se tenga sobre el ser humano equivale a un juicio sobre este. En cuanto al Inquisidor, es su conocimiento de la endeblez de la humanidad lo que le da el derecho de juzgarla: él sabe que un ser tan débil como el hombre en general no puede aspirar a mantener la autonomía en el juicio de sí mismo y deberá rendirse a lo que decidan sobre él los pocos hombres más fuertes. Además, está convencido de que, si a las personas no se les prohíbe el mal, más rápido que tarde se lanzarán a vicios crueles y oprobiosos, que solo la férrea mano de la autoridad consigue evitar ${ }^{7}$.

Al cuestionamiento que podría hacérseles a ambos acerca de su derecho a juzgar, la respuesta sería similar. ¿Quiénes son ustedes para juzgar?, es la pregunta clave, y la respuesta no se hace esperar: "Juzgamos al ser humano porque lo conocemos." Quien se abstiene de juzgar lo hace porque la ignorancia se lo impide; si se conocen los hechos, automáticamente se está juzgando. En el caso del Inquisidor, llama la atención que este pretende conocer al género humano mejor que el Cristo con el cual se enfrenta (ya se ha visto que en el fondo no le reconoce a este una sapiencia divina, sino que lo considera un impostor al pretenderse Dios); su posición no será nunca la de un creyente que deja en Dios tanto el acceso al conocimiento total como la capacidad de juzgar. (Una humildad de este tipo rara vez la han exhibido los miembros de las iglesias, siempre propensos al anatema.) En cuanto a Clamence, este se pretende conocedor del género humano por su capacidad para verse a sí mismo; cree que quien mira dentro de sí con agudeza consigue al mismo tiempo mirar dentro de los otros, que son sus semejantes. Aquí viene a cuento recordar la crítica principal (en mi opinión, la más fundada también) que Michel Onfray lanza sobre Freud en El crepúsculo de un ídolo: la rapidez con que generaliza para todo el mundo lo que descubre al interior de su particular aparato psíquico viene a ser uno de los puntos más débiles del psicoanálisis. Lo mismo se puede decir de Clamence: tiene derecho a forjar una imagen de su propia persona, la cual no le gusta, y nadie discutirá la validez íntima de esta, pero ¿no va muy aprisa cuando pretende que todo el mundo se le parece? Y ¿no es esta precipitada culpabilización de los demás una forma de disminuir la culpa que siente sobre sí mismo, al "diluirla" sobre toda la humanidad?

Creo que aquí estriba el error de ambos personajes, error que -en textos complejos como estos, que no pretenden darles a los lectores sus conclusiones ya masticadas - se podría pasar por alto. Tengo la impresión de que así ocurrió, sobre todo con La chute: no todo el mundo parece darse cuenta de que el personaje de Clamence demuestra estar equivocado ${ }^{8}$. Y, sin embargo, debería tenerse ya conciencia de una estrategia que Camus a menudo desarrolla: darles voz a los errores que son verdaderamente importantes, pues solo así es posible evitarlos. Es preciso entenderlos a cabalidad, ya que no se trata de errores burdos, cometidos por mera estulticia, sino de equivocaciones con un fuerte fundamento, que es preciso examinar para encontrarles el punto flaco. Esto ya lo habíamos visto en Calígula, la pieza teatral dedicada a expresar los excesos del absurdo político, y en El extranjero, la novela en la que el protagonista 
se convierte en asesino por su incapacidad de reacción ante el absurdo existencial. Es una estrategia que Camus ha aprendido creo-de Dostoievski, el gran maestro en dejar hablar a aquellos con los que difería, lo cual es consubstancial - como lo hace notar Bajtín —a la novela dialógica. Ahora bien, a menudo en las obras de Dostoievski los adversarios de las ideas del autor terminan por ganarse el crédito con los lectores, algo en lo que intenté profundizar en un ensayo anterior llamado "Dostoievski versus Dostoievski” (Víquez, 2009a). Que lo mismo, con algunos matices distintivos, le pueda pasar a Camus, no debería sorprender.

Volviendo al error que el Gran Inquisidor y Clamence cometen, diré que se trata de una generalización apresurada del mal. Clamence generaliza su propia mala conciencia, como si no hubiera en el mundo nadie capaz de actuar bien sin inscribir ese bien entre líneas torcidas que lo tornan en mal. El Inquisidor generaliza el miedo del ser humano a la libertad, como si este temor estuviera escrito en piedra en la esencia humana, y no es demasiado riguroso en su razonamiento, ya que está dispuesto a admitir - la suya personal, la primeraexcepciones al respecto. El error se fundamenta en el silencio que ambos personajes provocan en el otro: cuando el Inquisidor se niega a escuchar al Cristo, así como cuando Clamence no le cede un espacio para hablar a su interlocutor, la posibilidad de que rectifiquen se evapora. En este sentido, en ambos casos se demuestra que el aislamiento de los jueces conduce a juicios erróneos, o más aún, que la gente se convierte en un mal juez de los otros cuando cesa de escucharlos. Además, ambos personajes se hacen portadores de una autoridad -recuérdese que, aunque falsos, son papas de hechoproveniente en primer lugar del desprecio que sienten por los demás, lo cual-según ellos-- les da el derecho de decidir por los otros ${ }^{9}$.

A esta generalización apresurada del mal, se suma el hecho de que los personajes responden al mal que ven con una solución apenas parcial. Se diría que piensan que el mal fundamental (diferente en cada caso, según ya vimos) con trabajos se puede maquillar. El inquisidor propone una esclavitud ciega que pueda al menos hacer felices a los mediocres; Clamence se propone difundir una culpa entre todos los que lo escuchen que tal vez aclararía la supuesta verdad, pero no cambia nada: recuérdese que, ante la eventualidad de presenciar otra caída de una joven en el Sena, Clamence prevé que no se lanzará. Ahora bien, no se trata de que renuncien a actuar por causa de esta incapacidad para solucionar a fondo el problema del mal: muy al contrario, vemos en ambos una dedicación exclusiva que bien se puede llamar obsesión, coincidente, en el caso de Clamence, con la opinión de Sartre de que la culpa mueve a la acción. En el caso de Dostoievski, el Gran Inquisidor viene a ser uno más de sus personajes característicos, ya que, como señala Bajtín (1988), en este autor cada personaje importante actúa movido por una idea fundamental.

Pienso que, si generalizar el mal conduce a estos errores, quizás sea mejor generalizar el bien. Vuelvo a Los hermanos Karamázov: la antítesis del pensamiento del Gran Inquisidor se podría ver expresada en el discurso final de Aliosha, durante el entierro del pequeño Iliusha. Allí se expresa la fe en que los seres humanos son capaces de aferrarse a la bondad libremente, sin que medie la amenaza del castigo ni la mezquina esperanza de la recompensa, sin que el miedo de saberse libres se traduzca en infelicidad, sino más bien en responsabilidad por los propios actos. Pues la bondad ejerce - según Alioshauna fascinación sobre las almas libres, que por ser libres pueden volverse hacia el mal, pero si recuerdan lo que es la bondad, sabrán volver a ella: “...por malos que nos volvamos, y Dios no lo quiera, cuando recordemos cómo hemos enterrado a Iliusha, cómo lo hemos querido estos últimos días y cómo hemos hablado ahora frente a esta piedra, tan unidos y juntos, jni el más cruel de nosotros y más mordaz, si es que nos volvemos así, se atreverá en el fondo de su alma a burlarse de haber sido tan bueno y sensible en este momento de ahora! Es más, quizá precisamente este recuerdo lo retenga y lo prive de cometer una acción nefasta, lo haga 
recapacitar y decirse: 'Sí, yo entonces era bueno y honrado."” (Dostoievski, 1983: 932 ${ }^{10}$ ).

En cuanto a Camus y la generalización del bien, me remito a la reflexión final de $L a$ peste: el doctor Rieux da testimonio a favor de los seres humanos cuando reflexiona que "...ce qu'on apprend au milieu des fléaux, c'est qu'il y a dans les hommes plus de choses à admirer que de choses à mépriser" (Camus, 1947: 279) En el balance final de este personaje, que al contrario de Clamence, sí ha escuchado a los otros, no lleva las de ganar esta propagación del mal por causa de la mala conciencia, sino la convicción de que la solidaridad y la bondad entre las personas pueden no darse libres de problemas, pero al final son más importantes que las objeciones con que se cuestionan. Este, como es obvio, es otro texto, pero si tratamos a Camus como el pensador siempre coherente que fue, entendemos que realmente quiso oponer a Rieux y a Clamence, haciendo de este último el personaje en el error, como lo indican por lo demás algunas de sus declaraciones ${ }^{11}$.

Ahora bien, ni Aliosha ni Rieux nos ofrecen garantías. El hecho de que sus adversarios se equivoquen al pensar necesariamente mal de los seres humanos no implica que deba pensarse necesariamente bien de estos. Cuando Aliosha prevé que él o los muchachos que lo escuchan al dar su discurso podrían volverse malos, o cuando Rieux admite que junto a lo admirable del ser humano se encuentra lo despreciable, se nos demuestra que estos dos personajes no viven en la ilusión de un mundo sin mancha. Afirman, sin embargo, que es nuestro deber darles la oportunidad a las personas para que demuestren que la libertad humana a veces (¿muchas veces?) logra producir el bien.

\section{Notas}

1. Digo esto sin pasar por alto que, en el pasaje que comento, la otra voz, la de Aliosha Karamázov, también se hace escuchar. Estamos tan solo parcialmente ante un skaz. Dunwoodie (1996) sostiene que Margan-Shardt se equivoca del todo en relación con esto.
2. Aclaro que Davison cita a Dostoievski en la traducción francesa que conoció Camus, quien no hablaba el ruso.

3. También Dunwoodie cita a Dostoievski en francés.

4. El Gran Inquisidor está de hecho, aunque no de derecho, ejerciendo como tal. En cuanto a Clamence, durante su pequeña estancia en prisión, sus compañeros lo eligieron -entre veras y burlascomo "papa", en razón de la necesidad de contar con un poder que evitara los problemas internos.

5. No lo persigue la policía, aunque podría hacerlo: Clamence esconde en su casa una valiosa pintura robada. Pero expongamos el caso en su justa dimensión: este "crimen" no tiene nada que ver con la culpa original que lo atormenta; es apenas un efecto incidental de su vida en la marginalidad de Amsterdam, a la cual él se condenó de previo.

6. Existe un antecedente biográfico del incidente: la esposa de Camus intentó suicidarse lanzándose al vacío. Aparentemente, cuando ella leyó luego esta novela, le dijo a su marido: "Esta me la debes".

7. Dostoievski mismo parece haber compartido este último temor, si nos fiamos de cuán a menudo sus personajes, como Stavroguin en Los demonios, Raskólnikov en Crimen y castigo o el mismo Iván Karamázov, se precipitan hacia el mal una vez que no encuentran un freno a su libertad en la figura de un Dios autoritario. Sobre este asunto, más complejo de lo que cabe exponer ahora, he ahondado en "Dostoievski versus Dostoievski" (Víquez, 2009a).

8. ¿Acaso fue Sartre uno de quienes no entendieron esto? Eso sería objeto de otra investigación.

9. Clamence decide, por ejemplo, cómo repartir el agua, tan escasa en su cautiverio que era cosa de vida o muerte, y no le tiembla el pulso al tener en sus manos la suerte extrema de los otros. En cuanto al Inquisidor, dedicado a enviar gente a la hoguera, está de más decir que ejerce la autoridad sin ningún remordimiento.

10. Hace mal Aliosha al meter a Dios en esto. Me refiero al "y Dios no lo quiera". Es un error quizás meramente al expresarse, porque Aliosha apuesta por la libertad humana. Si alguien se hace malo no es porque Dios así lo quiso. 
11. Las recoge Elizabeth Trahan (1966: 344). Camus se refirió a La chute como un estudio satírico de una clase pervertida y poco saludable de solidaridad, y a Clamence como a un nihilista que exalta la servidumbre, un personaje muy lejano a la persona del autor.

\section{Bibliografía}

Bajtín, Mijaíl. 1988. Problemas de la poética de Dostoievski. (Traducción de Tatiana Bubnova). Fondo de Cultura Económica, México D.F.

Berdiaev, Nicolas. 1978. El espiritu de Dostoievski. (Traducción de Marcela Solá). Ediciones Carlos Lohlé, Buenos Aires.

Camus, Albert. 1956. La Chute. Editions Gallimard, Paris.

Camus, Albert. 1951. L'homme revolté. Editions Gallimard, Paris.

Camus, Albert. 1957. L'Etranger. Editions Gallimard, Paris.

Camus, Albert. 1951. Le mythe de Sisyphe. Editions Gallimard, Paris.

Camus, Albert. 1958. Caligula. Suivi de Le malentendu. Editions Gallimard, Paris.

Camus, Albert. 1947. La peste. Editions Gallimard, Paris.

Camus, Albert. 1994. Le premier home. Editions Gallimard, Paris.

Caraway, James E. 1992. "Albert Camus and the Ethics of Rebellion". Mediterranean Studies, Vol. 3, Penn State University Press.
Davison, Ray. 1997. Camus: The Challenge of Dostoevsky. University of Exeter Press, Devon, U.K.

Dodd, W.J. 1992. Kafka and Dostoevsky. The Shaping of Influence. St. Martin's Press, London.

Dostoievski, Fiódor. 1964. Crimen y castigo. (Traducción de José Fernández). Editorial Juventud, Barcelona.

Dostoievski, Fiódor. 1980. Los demonios. (Traducción de Luis Abollado). Bruguera, Barcelona.

Dostoievski, Fiódor. 1983. Los hermanos Karamázov. (Traducción de Augusto Vidal). Bruguera, Barcelona.

Dostoïevski, Fedor. 1951. Journal d'un écrivain. (Traduction de Jean Chuzeville). Gallimard, Paris.

Dunwoodie, Peter. 1996. Une histoire ambivalente.: le dialogue CamusDostoïevski. Librérie Nizet, Paris.

Friedman, Maurice. 1970. Problematic Rebel: Melville, Dostoievsky, Kafka, Camus. The University of Chicago Press, Chicago.

Hoffmann, Leon-Francois. 1969. "Une source de La Chute: Monsieur de Bougrelon". Revue d'Histoire littéraire de la France, 69 Année, N. 1, Presses Universitaires de France: 93-100.

Just, Daniel. 2010. "From Guilt to Shame: Albert Camus and Literature's Ethical Response to Politics" MLN, 124(4), Sept: 895 - 912.

Miscin, Daniel. 2007. "Some Remarks on the Theodicy of Ivan Karamazov". http:// www.fyodordostoevsky.com/essays.php. Consulta: 10 de agosto de 2015 . 
Onfray, Michel. 2011. El crepúsculo de un ídolo. (Traducción de V. Villacampa) Editorial Taurus, Madrid.

Pasqua, Hervé. 1990. “Albert Camus et le probleme du mal". Les Etudes Philosophiques, N. 1 (Janvier-Mars), Presses Universitaires de France, pp. 49-58.

Politzer, Heinz. 1960. "Franz Kafka and Albert Camus: Parables of our time". Chicago Review, 14(1, Spring): 47-67.

Rossi, Louis R. 1958. "Albert Camus: The Plague of Absurdity". The Kenyon Review, 20(3, Summer): 399-422.

St. Aubyn, F.C. 1957. "Albert Camus: Dialogue or Monologue?" Books Abroad, 31(2, Spring), University of Oklahoma: 122-125.

Stern, Daniel. 1998. "The Fellowship of Men that Die: the Legacy of Albert Camus". Cardozo Studies in Law and Literature, 10(2, Winter): 183-198.

Trahan, Elizabeth. 1966. "Clamence vs. Dostoievsky: An Approach to La Chute". Comparative Literature, 18(4, Autumn): 337-350.
Todorov, Tzvetan. 1991. Crítica de la crítica. (Traducción de José Sánchez Lecuna) Paidós, Barcelona.

Vega, José María y Neus Carbonell. 1998. La literatura comparada: principios $y$ métodos. Gredos, Madrid.

Víquez, Alí. 2009a. "Dostoievski versus Dostoievski”. Revista de Filología y Lingüistica, 35(2), Universidad de Costa Rica: 49-77.

Víquez, Alí. 2009b. "Los hombres de Dostoievski”. Revista de Filología y Lingüistica, 35(1), Universidad de Costa Rica: 87-110.

Yalom, Marilyn K. 2003. "Albert Camus and the Myth of The Trial". Modern Language Quarterly, 25(4): 434-450.

Zepp, Evelyn. 1982. "The generic ambiguity of Albert Camus' La Chute". French Forum, 7(3, September), The University of Nebraska Press: 252-260.

Zepp, Evelynn. 1983. "The Popular Ritual Structural Pattern of Albert Camus' $L a$ Chute". Modern Language Studies, 13(1, Winter): 15-21.

\section{(C) $\mathbb{( \mathbb { X } \Theta \Theta}$}

Este obra está bajo una licencia de Creative Commons Reconocimiento-NoComercial-SinObraDerivada 4.0 Internacional. 